\title{
Redesain Pasar Mangiran di Bantul D.I. Yogyakarta yang Mewadahi Kegiatan Ekonomi, Sosial, dan Budaya yang Berkelanjutan
}

\author{
Nicolaus Nino Ardhiansyah ${ }^{1}$, Rony Gunawan Sunaryo ${ }^{2}$, Elisabeth Kirana Angesti Prasetya ${ }^{3}$ \\ Departemen Arsitektur, \\ Universitas Atma Jaya Yogyakarta, Jl. Babarsari No. 44, Janti, Caturtunggal, \\ Kec. Depok, Kabupaten Sleman, Daerah Istimewa \\ Yogyakarta \\ Email: nino.ardhiansyah@uajy.ac.id ${ }^{1}$
}

Received: January 27, 2022 ; Revised: -; Accepted for Publication: February 23, 2022; Published: March 1, 2022

\begin{abstract}
Traditional Markets provide employment and become the main source of life for many people. Based on data from the Ministry of Trade, there are 13,450 Traditional markets that accommodate 12.6 million traders. Seeing the very large number, it proves that the Traditional Market is an important substance in people's lives.

Mangiran Traditional Market is one of the Traditional Markets located in Bantul Regency, DIY. This market is one of the locations included in the Revitalization of 32 Traditional Markets program implemented by Bappeda Bantul. Mangiran Traditional Market has a very strategic development potential because it is on the main route to NYIA Airport, besides that it also has a fairly high historical value.

Mangiran Traditional Market based on SNI is included in the Type III Traditional Market. Based on the results of the analysis of the SNI table, there are several facilities that are not yet available in this market, so that it affects the comfort of visitors.

The redesign of the Mangiran Traditional Market which is able to accommodate sustainable economic, social, and cultural activities is a consideration to increase the convenience of managers, traders, and buyers. The word sustainable is important because the market is expected not to lose its identity but still be able to compete in this modernization era.
\end{abstract}

Keywords: Traditional Market, Mangiran Traditional Market, SNI, Sustainable

\footnotetext{
Abstrak - Pasar Rakyat menyumbangkan lapangan kerja dan menjadi sumber utama kehidupan bagi banyak orang. Berdasarkan data Kementrian perdagangan terdapat 13.450 pasar rakyat yang menampung sebanyak 12,6 juta pedagang. Melihat jumlah yang sangat besar, membuktikan Pasar Rakyat menjadi substansi penting dalam kehidupan masyarakat.

Pasar Mangiran merupakah salah satu Pasar Rakyat yang terdapat di Kabupaten Bantul, DIY. Pasar ini menjadi salah satu lokasi yang masuk ke dalam program Revitalisasi 32 Pasar Rakyat yang dilaksanakan oleh Bappeda Bantul. Pasar Mangiran mempunyai potensi pengembangan yang sangat strategis karena berada di jalur utama menuju Bandara NYIA, disamping itu juga mempunyai nilai historis yang cukup tinggi.

Pasar Mangiran berdasarkan SNI masuk kedalam Pasar Rakyat Tipe III. Berdasarkan hasil analisis tabel SNI ada beberapa fasilitas yang belum tersedia di pasar ini, sehingga mempengaruhi kenyamanan pengunjung.
}

Redesain Pasar Mangiran yang mampu mewadahi aktivitas ekonomi, sosial, dan budaya yang berkelanjutan menjadi pertimbangan untuk meningkatkan kenyamanan pengelola, pedagang, dan pembeli. Kata berkelanjutan menjadi penting karena pasar diharapkan tidak kehilangan jati dirinya namun tetap bisa bersaing diera modernisasi ini.

Kata Kunci : Pasar Rakyat, Pasar Mangiran, SNI, Berkelanjutan

\section{PENDAHULUAN}

Pasar Rakyat adalah tempat bertemu penjual dan pembeli secara langsung yang terjadi proses yang lebih organik dimana adanya tawar menawar sehingga aktivitas menjadi lebih intim antara pelaku. Selain menjadi tempat aktivitas ekonomi, pasar rakyat yang sudah ada di tengahtengah masyarakat sejak dahulu juga menjadi tempat berkumpul dan bersosialisasi bagi beberapa kelompok tertentu. Karena itu pasar rakyat juga memiliki fungsi sosial disamping fungsi ekonomi sebagai kegiatan utamanya.

Dalam kurun waktu 5 tahun terhitung dari 2015, perdagangan menjadi salah satu faktor yang turut menggerakan perekonomian provinsi D.I.Yogyakarta. Menurut Data Produk Domestik Regional Bruto D.I.Y menunjukkan bahwa sektor perdagangan berdampak pada bergeraknya roda perekonomian. Program dari Badan Perencanaan Pembangunan Daerah (Bappeda) Bantul untuk merevitalisasi 32 pasar di wilayah Kabupaten Bantul menjadi latar belakang proyek ini. Program dilaksanakan untuk meningkatkan perekonomian masyarakat dan meningkatkan kenyamanan masyarakat ketika berbelanja di pasar rakyat. [1]

Pasar Mangiran berada dilokasi yang sangat strategis yakni berada di jalur utama menuju ke New Yogyakarta International Airport (NYIA). Hal ini menjadi pertimbangan Bappeda Bantul untuk memberikan daya tarik lebih Pasar Mangiran agar dapat meningkatkan jumlah kunjungan wisatawan yang dari atau ke bandara untuk berkunjung ke Pasar Mangiran.

Beberapa stigma yang menyebabkan masyarakat enggan berbelanja di Pasar Rakyat 
Redesain Pasar Mangiran di Bantul D.I.Yogyakarta yang Mewadahi Kegiatan Ekonomi, Sosial, dan Budaya yang Berkelanjutan

antara lain adalah pasar yang kotor, panas, kumuh, dan berbau tidak sedap (Dinas Perdagangan Kabupaten Bantul, 2019). Hal ini juga terjadi didalam Pasar Mangiran dimana nampak pada kondisi eksisting pasar. Pasar Mangiran memiliki beberapa kekurangan yang membuat pembeli dan pedagang tidak nyaman dalam beraktivitas. Adapun beberapa kekurangan tersebut adalah: tidak adanya zonasi yang jelas sesuai dengan jenis komoditas yang dijual di pasar, kurangnya kapasitas los yang membuat pedangang lebih suka berjualan di pinggir daripada berdesakan di los yang disediakan, kurangnya kapasitas parkir, dan muka bangunan yang kurang mengekspresikan kekhasan arsitektur Yogyakarta yang representatif.

Selain sebagai penujang kegiatan perekonomian masyarakat, pasar tradisional juga menjadi sebuah ikon bagi suatu daerah. Kekhasan arsitektur Yogyakarta sebagaimana tercantum di Perda DIY no.1 tahun 2017 mengenai Arsitektur Bangunan erciri Yogyakarta juga harus terlihat dari pasar tradisional untuk menjadi sebuah daya tarik tersendiri (PerDa DIY, 2017). Kabupaten Bantul sendiri adalah salah satu sentra budaya dimana banyak komunitas dan kalangan seni yang berkembang di Bantul.

Pasar juga bisa menjadi wadah bagi berkumpul dan berkarya bagi komunitas seni yang ada di suatu daerah. Menurut kepala kecamatan Kapanewon, kesenian di Bantul cukup berkembang dan butuh diwadahi di pasar tradisional untuk berkarya. Sedangkan pada bangunan eksisting tidak terdapat ruang khusus yang memungkinkan para komunitas seniman yang ada untuk berkumpul dan berkarya bersama. Hal ini menuntut pasar dapat menjadi mixed-use sehingga selain untuk mewadahi kegiatan perekonomian, namun juga memberi tempat untuk terjadinya proses sosial-budaya bagi para komunitas seni di Kabupaten Bantul.

Bagaimana mewujudkan rancangan Redesain Pasar Mangiran di Kabupaten Bantul, D.I.Yogyakarta yang dapat mewadahi kegiatan ekonomi, sosial, dan budaya yang berkelanjutan dan mampu merepresentasikan ciri khas arsitektur Yogyakarta menjadi rumusan masalah yang akan diselesaikan dalam kegiatan pengabdian ini.

\section{METODE PENGABDIAN}

Metode pencarian data yang akan digunakan merupakan data primer yang didapat melalu survey lokasi dan data dari Bappeda Bantul, serta data sekunder yang didapatkan dari internet, situs pemerintah, dan literatur terkait.

Metode analisis data menggunakan metode analisis programatik, dimana menganalisis data yang telah didapatkan menggunakan standar yang ada dalam hal ini persyaratan teknis SNI terkait
Pasar Rakyat dan beberapa jurnal terkait revitalisasi pasar rakyat.

\section{A. Profil Eksisting}

Pasar Mangiran berlokasi di Jalan Srandakan KM 2, Pedak, Trimurti, Bantul, Daerah Istimewa Yogyakarta, yang merupakan jalur utama yang menghubungkan Kabupaten Bantul dan Kulonprogo.

Pasar Mangiran dibangun sejak jaman penjajahan Belanda. Aktivitas pasar dimulai dari pukul $02.00 \mathrm{~s} / \mathrm{d} 04.00 \mathrm{WIB}$ untuk pedagang pisang, kemudian pukul 10.00 s/d 08.00 WIB untuk pedagang kelapa dan unggas, sedangkan aktivitas keseluruhan pasar dimulai dari pukul 04.00selesai.[2] Luas lahan pasar yakni $4.355 \mathrm{~m} 2$, sedangkan luas bangunannya sebesar $2.433 \mathrm{~m} 2$. Status lahan Pasar Mangiran yakni Sultan Ground. Pasar Mangiran buka setiap hari pasar Wage dan Pahing. [4]

Pasar Mangiran berbatasan dengan permukiman warga pada bagian timur, barat dan selatan bangunan, dan jalan raya utama pada bagian utara.

Mayoritas pedagang berasal dari bantul dan Kulonprogo. Mereka datang ke Pasar Mangiran untuk menjual barang yang didapat langsung dari petani.

\section{B. Data Eksisting}

Zonasi Eksisting Pasar Mangiran dapat dikelompokkan menjadi 4 zona. Zona 1 meliputi kios warung makan, minum, dan snack, Zona 2 meliputi lesehan pedagang alat (baju, aneka cemilan, jajanan pasar, dan perkakas rumah tangga), Zona 3 meliputi lesehan pedagang penjual bahan masak (daging, bumbu/rempah, dan sayur), dan Zona 4 meliputi fasilitas umum (toilet, mushola, dan TPS).

Pasar Mangiran terdapat Kios dan Lesehan, namun tidak ada Los pada area pasar ini. Ukuran eksisting kios 3x3 m2, sedangkan untuk ukuran lesehan cukup bervariasi diantaranya : $3 \times 2,7 \mathrm{~m} 2$, $3 \times 2,5 \mathrm{~m} 2$, dan $3 \times 2.25 \mathrm{~m} 2$.

Akses masuk utama pasar berada disisi utara pasar, sedangkan akses belakang pasar berada di sisi selatan. Juga terdapat 4 akses pintu disetiap sisi pasar. Kapasitas area parkir masih terbatas, sehingga sebagian pengunjung pasar menggunakan area parkir yang berada pekarangan warga setempat. Warga sekitar secara tidak langsung juga mendapatkan nilai ekonomis dari keberadaan lahan parkir tersebut.

Saluran drainase pada area pasar banyak yang sudah rusak dan tampias, banyak pipa drainase yang pecah dan hanya dibalut dengan bungkus plastik dan karung untuk perbaikan sementara. Selain itu juga banyak pedagang yang memanfaatkan selokan drainase sebagai tempat berdagang. 
TPS Pasar berada diujung akses masuk utama. Pengguna pasar selalu membuang sampah pada bagian depan TPS, sehingga ada beberapa sampah yang berserakan. Tenaga kerja kebersihan hanya akan datang ketika pasar akan tutup untuk membuang sampah ke TPS piyungan.

Terdapat mushola pada pasar yang terletak di sudut pasar. Berdasarkan wawancara terhadap pedagang, mushola sudah berjalan sesuai fungsinya dengan baik. Kondisi mushola juga terawat dan bersih. Tersedia 2 unit toilet dengan masing-masing 3 bilik. Satu unit didepan/sebrang mushola, dan satu unit disebelah sumur. Tidak ada masalah dengan distribusi air bersih, kebersihan toilet juga terjaga dengan baik. Kekurangannya, toilet tidak tertutup, padahal bukan area umum/publik. Ketika selesai menggunakan toilet, pengunjung langsung berhadapan dengan pedagang pasar. Toilet juga tidak memiliki pembagian pria dan wanita.

Pengelola Pasar terdiri dari 1 koordinator pasar, 1 bendahara/Pembina dagang, 1 sekretaris/dana bergulir, 2 pembina dagang/ kamtib, 1 pembina dagang/koor kebersihan, 1 bagian umum, dan APPSI. Aksesibilitas dan kenyamanan kantor pengelola masih rendah, karena posisi kantor yang sulit diakses dan dimensi ruangan yang tidak memenuhi standar kenyamanan ruang.

Akses jalan masuk utama cukup besar untuk dilewati mobil/pickup. Namun ditengah-tengah jalan terdapat pedagang yang menggelar dagangannya, sehingga menutupi jalan. Sedangkan Akses jalan di dalam pasar cukup sempit dan barang dagangan milik pedagang sering menutupi jalan.

\section{Harapan}

Pengguna Pasar Mangiran memiliki beberapa harapan, diantaranya :

1. Harapan Pengelola Pasar dan Instansi terkait :

a. Kreativitas desain bangunan.

b. Oleh karena desain pasar eksisting sangat tertutup, diharapkan membuat desain yang terbuka kedepannya, sehingga saat orang lewat didepan pasar akan tahu bahwa pasar sebenarnya rama. Diharapkan dengan desain yang baru, jumlah pengunjung akan meningkat.

c. Desain diharap mampu membuat pedagang yang bermodalkan terpal untuk pindah kedalam pasar

d. Area parkir masuk kedalam pasar, namun yang mengelola tetap perwakilan warga.

e. Pasar memenuhi SNI.

f. Desain ikonik, sejahtera, bangunan yang terdapat budaya khas jogja.

g. Desain keberlanjutan.

h. Sirkulasi persampahan yang ramah lingkungan, sirkulasi persampahan baik, dan menjadi sumber daya. i. Memiliki ruang bagi seniman untuk tampil.

j. Memanfaatkan keunggulan bantul, yakni seni budaya, kuliner, dan perdagangan.

2. Harapan Pedagang

a. Atap yang sudah bocor dibenarkan.

b. Agar saat hujan aman.

c. Tidak menginginkan adanya pembangunan ulang, kalaupun terpaksa dibangun kembali diharapkan dapat ditempatkan dilokasi semula,

\section{HASIL DAN PEMBAHASAN}

\section{A. Analisis SNI}

Berdasar Standar Nasional Indonesia (SNI) nomor 8125 tahun 2015, Pasar Mangiran termasuk pasar rakyat tipe III dilihat dari banyaknya jumlah pedagang.[5] Berdasarkan SNI, maka dilakukan survey untuk mengetahui kondisi eksisting pasar mangiran saat ini, ruang-ruang yang telah memenuhi standar yang diterapkan, dan ruang-ruang yang memerlukan perbaikan. Hasil Survey menunjukkan bahwa ada beberapa sarana prasarana yang belum dipenuhi oleh Pasar Mangiran diantaranya : Area bongkar muat barang, pos ukur ulang, tempat penyimpanan suhu rendah, ruang menyusui, CCTV, ruang bersama, pos kesehatan, pos keamanan, area merokok, ruang disinfektan, area penghijauan, kenyamanan anak tangga, kenyamanan meja berjualan, akses untuk kursi roda, jalur evakuasi, tabung pemadam kebakaran, hidran air, pengujian kualitas air bersih, pengujian limbah cair, alat angkut sampah, dan pengelolaan sampah berdasarkan $3 \mathrm{R}$.

\section{B. Analisis SWOT}

Berikut hasil analisis SWOT dari Pasar Mangiran di Kabupaten Bantul :

1. Strengths (Kekuatan)

a. Lokasi terletak di jalan strategis yaitu J1. Srandakan yang merupakan jalur akses antara Kabupaten Bantul-Kulonprogo.

b. Dekat dengan Bandara, dapat dijadikan lokasi transit dan destinasi wisata dan seni bagi wisatawan nasional maupun internasional

c. Disekitar lokasi banyak terdapat permukiman warga, sehingga mudah mendapat pembeli

d. Lebar jalur kendaraan yang besar sehingga sirkulasi kendaraan lebih lancar

e. Telah berdiri sejak masa penjajahan Belanda/Jepang, sehingga memiliki nilai sejarah yang lebih

2. Weakness (Kelemahan)

a. Luas lokasi terbatas/sempit.

b. Keterbatasan lahan parkir.

c. Kurang menarik pada penataan lansekap. 
d. Sirkulasi (pejalan kaki, pesepeda, motor, mobil) Pasar Mangiran yang tercampur menjadi satu sehingga kurang nyaman.

e. Minimnya vegetasi yang ada pada lokasi.

f. Tempat pembuangan sampah yang belum tertata.

g. Penataan sarana dan prasarana serta zonasi pedagang yang masih berantakan dan kurang memadai.

h. Lemahnya ikon untuk menarik pengunjung datang.

i. Waktu buka yang hanya $2 \mathrm{x}$ dalam kalender jawa, kurang menarik pengunjung.

3. Opportunities (Peluang)

a. Bentuk bangunan yang unik berpotensi menjadi obyek spot foto pengunjung.

b. Kegiatan malam dapat dijadikan lokasi nongkrong dan pertunjukkan malam.

c. Penambahan panggung kesenian untuk wadah para seniman Bantul.

d. Pasar tradisional dengan penataan yang baik dapat menarik minat pengunjung.

e. Lokasinya yang strategis dapat menjadi central makanan khas Bantul.

f. Kerajinan di Bantul yang berbagai macam.

g. Menggunakan konsep pasar Go Green untuk memberikan vegetasi serta pasar yang ramah lingkungan. [6]

4. Threats (ancaman)

a. Pasar tradisional disekitar Pasar Mangiran yang buka setiap hari dapat mengurangi daya tarik pengunjung.

b. Nilai sejarah berdirinya pasar sejak jaman penjajahan yang telah dapat berubah.

c. Perspektif masyarakat tentang pasar tradisional yang kumuh membuat pengunjung enggan datang.

d. Para pedagang lama yang sudah terlanjur memiliki pelanggan akan lebih susah untuk diatur penempatannya.

\section{Regulasi}

Koefisien Dasar Bangunan yang diacu berdasarkan peraturan terkait yaitu maksimal $60 \%$, sedangkan untuk KLB adalah 1.2. [7]

Pasar Mangiran terletak di Kecamatan Srandakan yang merupakan kawasan pertanian tanam pangan, peternakan, serta rumah kepadatan rendah hingga tinggi berdasarkan peta RDTR Kabupaten Bantul.[8]

Menurut Sistem Informasi Manajemen Kewilayahan Berbasis Webgis Kabupaten Bantul minimal Garis Sempadan Pagar (GSP) untuk ruas Srandakan adalah 4 meter, dan minimal Garis Sempadan Bangunan (GSB) 8 meter. [9]

Berdasarkan regulasi diatas maka dapat disimpulkan untuk : KDB maksimal 60\%, KLB 1,2,
RTH minimal 20\%, GSB minimal $8 \mathrm{~m}$, dan GSP minimal $4 \mathrm{~m}$. [7]

\section{Studi Preseden}

Studi preseden dilakukan pada 2 Tipologi Pasar Rakyat yang dirasa memiliki esensi dari desain yang akan dirancang pada Redesain Pasar Mangiran. Kedua pasar tersebut adalah Pasar Seni Ubud, dan Pasar Larangan Sidoarjo. [10]

\section{E. Analisis Site}

Berdasarkan survey penulis, didapatkan kondisi eksisting sebagai berikut :

A. Sirkulasi

1. Pagar pada bangunan sedikit, sehingga keamanan pasar pada malam hari tidak baik.

2. Area drop off bangunan hampir tidak ada, sehingga pengunjung harus berhenti di jalan dan menghambat arus lalu lintas.

3. Akses pada bangunan hanya ada 2 , dan melewati jalur utama yang ada di sebelah barat dan utara bangunan, jalur masuk langsung dari jalan raya sehingga sulit diketahui dan dulalui.

B. Vegetasi

1. Area terbuka hijau yang ada pada eksisting gersang dan kurang nyaman. Dapat dikatakan tidak ada dan memenuhi standar.

2. Kurangnya vegetasi membuat bangunan menjadi panas, disebabkan oleh tidak adanya bayangan alami dari pepohonan.

C. Drainase

1. Saluran air tidak berjalan dengan baik, sehingga air hujan akan menggenang disekitar bangunan.

2. Banyak area yang tempias karena beberapa bagian pada bangunan tidak tertutup dengan baik. Dapat juga dikarenakan oleh rusaknya sarana prasarana pasar seperti atap dan saluran air.

3. Saluran air tertutup pedagang.

D. Kebisingan

1. Area yang harusnya merupakan zona privasi, seperti mushola, berada di sekitar pedagang, sehingga cukup ramai dan dapat menganggu pengguna saat beribadah.

2. Kantor pengelola berada di lantai 2, namun terletak mengahdap jalan besar. Ruangan yang seharusnya private menjadi ramai dan kurang privasi.

3. Kebisingan utama datang dari jalan utama pada sisi barat bangunan.

E. Utilitas 
Redesain Pasar Mangiran di Bantul D.I.Yogyakarta yang Mewadahi Kegiatan Ekonomi, Sosial, dan Budaya yang Berkelanjutan

1. Kelistrikan pada bangununan dialirkan dari tiang listrik yang berjarak 3 meter dari jalan utama.

2. Pedagang mengambil air bersih dari keran yang disediakan kemudian dibawa ke area dimana mereka berdagang.

3. Area sampah dijadikan satu di sisi timur bangunan kemudian diangkut oleh petugas sampah.

\section{F. PROGRAMMING}

Dalam perencanaan dan perancangan Redesain Pasar Mangiran diperlukan analisis kebutuhan ruang sehingga mampu memenuhi SNI. Selain itu juga diperlukan analisis hubungan antar ruang guna menciptakan zoning yang mampu memudahkan dan memberi kenyamanan bagi para pengguna.

Berdasarkan hasil Analisis Kebutuhan Ruang didapatkan hasil sebagai berikut :

1. Minimum luas los adalah $4 \mathrm{~m}^{2}$ dengan total jumlah 300. Untuk kios, memiliki minimum luas $9 \mathrm{~m} 2$ dengan total 56.

2. Area parkir terbagi menjadi area parkir motor, becak, mobil, dan bus. Total minimum luas parkir mobil adalah 1.536 $\mathrm{m}^{2}$, luas parkir motor $243 \mathrm{~m}^{2}$, parkir bus $200 \mathrm{~m}^{2}$, dan becak $80 \mathrm{~m}^{2}$.

3. Area bongkar muat barang memiliki luas minimum $115 \mathrm{~m}^{2}$.

4. Koridor memanjang selebar $1,5-2 \mathrm{~m}^{2}$.

5. Pos ukur ulang minimum $1 \mathrm{~m}^{2}$, dengan jumlah 2 buah.

6. Kantor pengelola minimum $27,3 \mathrm{~m}^{2}$

7. Toilet dengan minimum luas $13,9 \mathrm{~m}^{2}$ untuk perempuan, dan $12 \mathrm{~m}^{2}$ untuk laki-laki. Dengan jumlah masing-masing 2 buah pada tempat yang berbeda.

8. Ruang menyusui memiliki total luas $4,6 \mathrm{~m}^{2}$ berjumlah 2 buah.

9. Ruang CCTV termasuk dalam ruang pengelola

10. Ruang ibadat seluas $300 \mathrm{~m}^{2}$.

11. Ruang bersama minimum $350 \mathrm{~m}^{2}$.

12. Pos Kesehatan seluas $15,5 \mathrm{~m}^{2}$.

13. Pos Keamanan minimum $3,8 \mathrm{~m}^{2}$.

14. Ruang Merokok minimum $7 \mathrm{~m}^{2}$.

15. Ruang Disinfektan alat minimum $3 \mathrm{~m}^{2}$.

16. Area Penghijauan minimum $40 \%$ dari luas bangunan.

17. TPS sementara minimum $100 \mathrm{~m}^{2}$.

\section{G. KONSEP PERANCANGAN DAN PERENCANAAN}

Pada desain yang baru, pasar mangiran diharapkan menjadi pasar rakyat yang dapat mewadahi berbagai kegiatan. Tisak hanya kegiatan jual beli, namun juga dari kegiatan kreatif masyarakat. Desain arsitektural Pasar Mangiran akan menggunakan konsep tradisional yogyakarta yang akan menjadi daya tarik wisatawan.

Konteks perencanaan fisikal pada desain merupakan batasan yang harus dipenuhi oleh desain baru. Yakni KDB maksimal $3.240 \mathrm{~m} 2$, KLB 1,2, RTH minimal 20\%, GSB minimal 8m, dan GSP minimal $4 \mathrm{~m}$.

Persyaratan perencanaan system manusia dapat diidentifikasi sebagai berikut : 400 pedagang (pelaku tetap), 4000 pembeli (pelaku tidak tetap), 400 pemasok (pelaku tidak tetap), 7 pengelola (pelaku tetap), 2 tukang parkir (pelaku tetap), dan 5 petugas kebersihan (pelaku tetap).

Sedangkan untuk persyaratan perencanaan dan fungsional ruang dapat dilihat pada tabel berikut

\section{Tabel 1.1. Persyaratan Perencanaan Fungsional} Ruang

\begin{tabular}{|l|c|c|}
\hline \multicolumn{1}{|c|}{ RUANG } & JUMLAH & DIMENSI \\
\hline Los & 300 & $4 \mathrm{~m}^{2}$ \\
\hline Kios & 67 & $9 \mathrm{~m}^{2}$ \\
\hline Toilet & 2 & $26 \mathrm{~m}^{2}$ \\
\hline Parkir & 1 & $3.456 \mathrm{~m}^{2}$ \\
\hline Ruang Merokok & 1 & $9 \mathrm{~m}^{2}$ \\
\hline Ruang Menyusui & 1 & $5 \mathrm{~m}^{2}$ \\
\hline Kantor Pengelola & 1 & $28 \mathrm{~m}^{2}$ \\
\hline Mushola & 1 & $207 \mathrm{~m}^{2}$ \\
\hline Ruang Bersama & 1 & $306 \mathrm{~m}^{2}$ \\
\hline Pos Kesehatan & 1 & $16 \mathrm{~m}^{2}$ \\
\hline Pos Ukur Ulang & 2 & $1 \mathrm{~m}^{2}$ \\
\hline $\begin{array}{l}\text { Tempat } \\
\text { Disinfektan }\end{array}$ & 1 & $3 \mathrm{~m}^{2}$ \\
\hline
\end{tabular}

Total Luas Lantai $1: 3.171 \mathrm{~m}^{2}$.

Tabel 1. Analisis Kebutuhan Ruang
Sumber : Analisis Penulis, 2021

\section{H. Konsep Perancangan Tapak}

Konsep desain menggabungkan 2 pendekatan konsep yang berkaitan, yakni arsitektur tradisional dan arsitektur hijau. Sisi tradisional pada desain ini dapat dilihat dari penggunaan material dan detai arsitektural pada bangunan. Sedangkan asritektur hijau dapat dilihat dari bentuk bangunan dan peletakan vegetasi pada bangunan. 


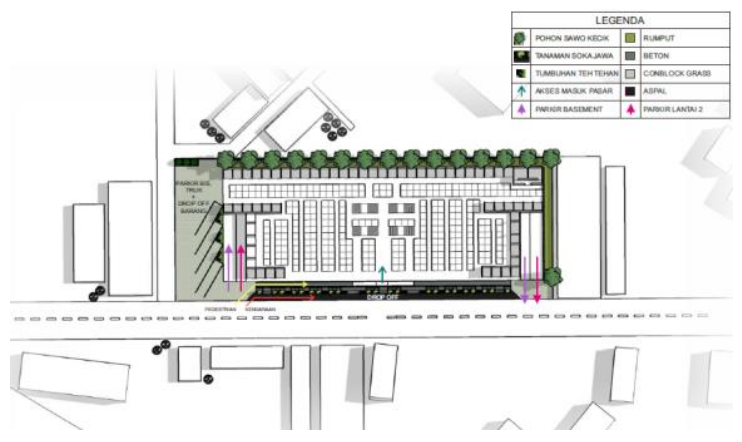

Gambar 1. Siteplan

Sumber : Analisis Penulis, 2021

\section{Transformasi Desain}

Arsitektur tradisional biasanya tidak jauh dari unsur alam, terutama arsitektur jawa dan filosofi-filosofinya. pada desain pasar mangiran, atap berbentuk segitiga menggambarkan gunungan. gunungan pada budaya jawa dapat menggambarkan 'gunung' pada alam, yang kemudian disederhanakan menjadi bentuk segitiga. Namun bentuk dari pegunungan dibuat tidak sejajar dan dinamis. Memiliki makna bahwa Arsitektur tradisional memang perlu dilestarikan, namun seiring berjalannya waktu, Arsitektur apapun harus menjadi adaptif, sehingga juga harus dapat menyesuaikan dan mengikuti perkembangan jaman. tidak hanya dari bentuk, tapi juga untuk kepengurusan pasar kedepannya. Pada bangunan juga terdapat taman dan rumput sintesis yang melambangkan hamparan padang rumput.

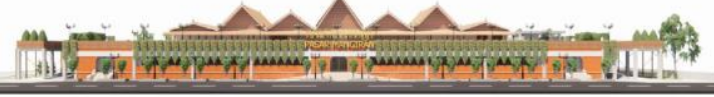

Gambar 2. Transformasi Fasad Bangunan Sumber : Analisis Penulis, 2021

\section{Konsep Perancangan Ruang}

Area basement digunakan untuk memenuhi masalah ketersediaan parkir. Dengan kapasitas 103 mobil, untuk masing-masing ukuran $3 \times 5$. Dan kapasitas motor 175 unit, dengan masing-masing ukuran 1x2. Area parkir basement juga menerapkan sirkulasi 1 arah.

Untuk lantai 1 berisikan 56 kios dengan ukuran 3x3, 300 los dengan masing-masing ukuran $2 \times 2$. Toilet disudut belakang, untuk toilet pria terdiri dari 3 bilik toilet dan 3 urinoir. Sementara untuk toilet wanita terdiri dari 4 bilik toilet. Untuk area tengah terdapat 4 buah tangga, 2 tangga dibelakang menuju parkir basement, dan 2 tangga didepannya menuju lantai 2.

Di lantai 2 terdapat area parkir kusus motor sebanyak 90 unit. Toilet pria yang terdiri dari 3 bilik toilet dan 3 urinoir, dan toilet wanita terdiri dari 4 bilik toilet. Mushola dengan ukuran 24x10, dilengkapi dengan area wudhu sebesar 6x6m. Ruang menyusui sebesar 6x2. Dan Kantor pengelolan sebear $6 \times 5 \mathrm{~m}$. Ruang bersama yang dapat digunakan untuk rapat meupun sosialisasi sebesar 36x10m. Dilantai 2 juga dilengkapi 10 kios untuk memperkenalkan kuliner khas kota Bantul bagi pengunjung pasar terlebih pengunjung yang ingin menikmati taman outdoor dilantai 2.

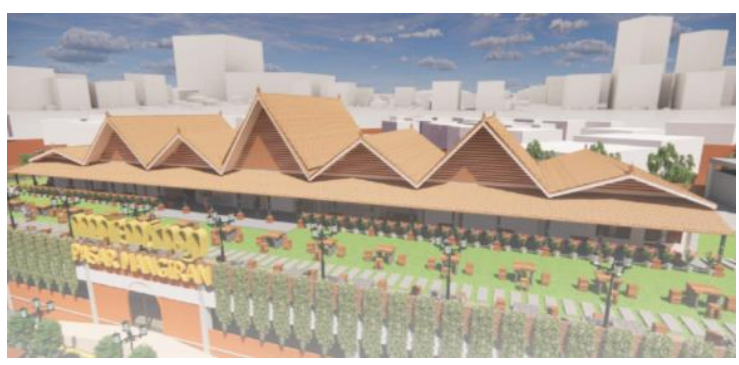

Gambar 3. Perspektif Lantai 2

Sumber : Analisis Penulis, 2021

\section{Penghawaan dan Pencahayaan}

Pencahayaan buatan akan digunakan dari sore-malam dengan penataan lampu difokuskan pada area kuliner dan kesenian. Lampu ruang luar dapat dijadikan aksen yang merepresentasikan kekhasan arsitektur Yogyakarta dengan permainan ornamen dan warna. Penghawaan pada bangunan akan memanfaatkan penghawaan alami semaksimal mungkin dengan sistem cross ventilation.

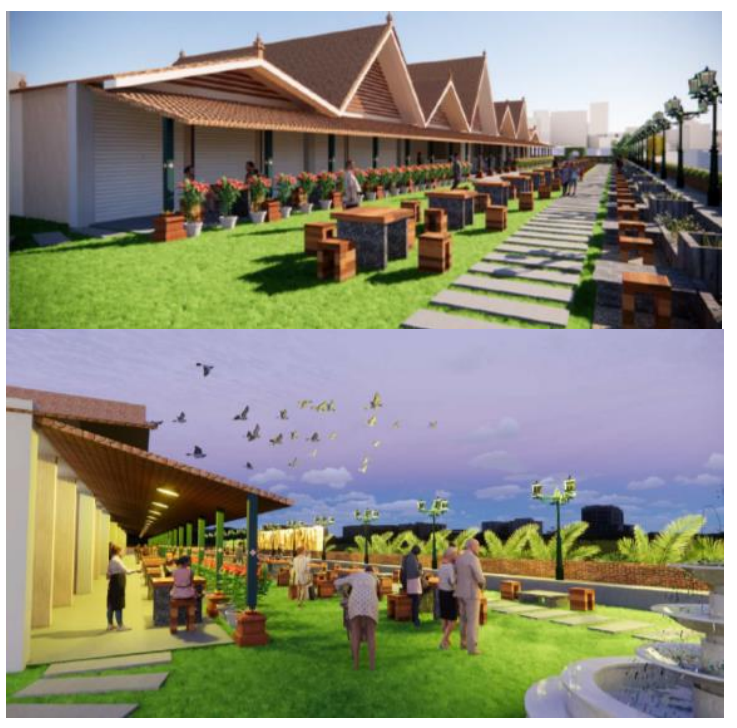

Gambar 4. Perspektif Area kuliner dan kesenian Sumber : Analisis Penulis, 2021

\section{Penerapan Konsep Arsitektur Tradisional}

Atap bangunan berbentuk segitiga yang merupakan hasil transformasi bentuk. yang melambangkan gunungan dalam budaya jawa. Eksterior dan interior bangunan diberikan aksen 
jawa seperti lampu gaya kuno dan detail ornamen rumah tradisional jawa.

Vegetasi yang digunakan bernuansa jawa dan asia diantaranya : Bambu Fragresia Rupa, Pohon Sawo Kecik, Tumbuhan Teh-tehan, Tanaman Soka Jawa, dan Lee Kwan Yew.

Terinsipirasi dari rumah joglo, umpak digunakan untuk mengokohkan tiang penyangga atap selasar. Beberapa ukiran kecil juga ditambahkan pada tiang ini untuk menambahkan detail arsitekturalnya. ukiran yang dapat dilihat pada tiang merupakan bentuk wajikan yang berisi bunga dan dedaunan yang dapat diletakkan terlentang atau berdiri. Pada bagian bawah tiang terdapat patran yang berarti daun. patran adalah hiasan yang menggambarkan daun yang berderet-deret. patran diartikan melambangkan kesempurnaan. Masyarakat Jawa mengasosiasikan warna hijau sebagai lambang alam sekitar yang juga bermakna "harapan hidup".

Penggunaan lampu gantung serta lampu dinding yang berbentuk klasik dapat memberikan kesan estetis pada detail arsitekturnya. Pemilihan cahaya lampu kuning juga untuk menambahkan kesan hangat pada bagian dalam pasar tanpa mengganggu dalam penglihatan.

Bata ekspos sebagai material utama fasad bangunan memiliki filosofi bersahaja dan hangat. selain itu batu bata juga merupakan material lokal dan mudah dijumpai. Serta material dinding yang dapat menyerap panas sehingga memberikan rasa sejuk pada pasar.

Batik kawung merupakan salah satu motif batik yang paling terkenal dari Yogyakarta, dengan bentuk yang disusun secara geometris. roster dengan motif batik kawung digunakan untuk menghiasi fasad depan Pasar Mangiran dengan keinginan untuk mengusung unsur-unsur budaya Yogyakarta dalam desain.

Lentera Jogja, atau lampu jalan antik yang menjadi lampu khas Malioboro kita gunakan untuk menghiasi pedestrian Pasar Mangiran. Tiang lampu yang bercabang tiga diharapkan selain menjadi penerangan juga dapat menjadi sarana untuk hiburan (berfoto), dan memancarkan kharisma tiang Lampu jalan budaya Yogyakarta, serta memiliki desain yang terlihat elegan dan mewah.

Atap pelana merupakan atap yang dibentuk dari pertemuan dua sisi bidang miring yang bertumpu pada garis lurus yang sama, di mana pertemuan ujungnya disebut bubungan. Bentuk atap pelana yang berundak merupakan hasil transformasi dari bentuk gunung. Pada kedua ujung bubungan diletakkan dua mahkuta. yang merupakan hiasan atap jawa yang memiliki arti raja (sultan kraton yogyakrata) sebagai utusan tuhan yang dapat memberi perlindungan kepada masyarakatnya. dapat juga diartikan sebagai mahkota wayang, dimana diharapkan orang yang hidup dan berkegiatan dalam bangunan tersebut diberi berkah.

\section{Mitigasi Bencana}

Penanggulangan kebakaran pasif dilakukan melalui jalur evakuasi yang dirancang menuju ke luar bangunan secara efektif. Penanggulangan kebakaran aktif dengan menggunakan hydrant dan sprinkler. Kebutuhan hydrant untuk Pasar Mangiran adalah 60.000 galon atau 228.000 liter, sedangkan kebutuhan Sprinkler sebanyak 4.725 galon atau 17.955 liter.

\section{Perancangan Utilitas Bangunan}

Perencanaan air bersih pada desain Pasar Mangiran menggunakan sumber utama PDAM dengan sistem down feed. Utilitas air bersih menggunakan groundtank dan uppertank.

Mekanisme pengelolaan sampah pada pasar sebagai berikut sampah dibuang ke tempat sampah yang tersebar di seluruh pasar, kemudian dibawa ke tempat pembuangan sementara yang ada di timur site. Lalu setiap sore dibawa ke tempat pembuangan akhir di Piyungan. Mekanisme pengelolaan sampah $3 \mathrm{R}$ masih terkendala terkait luasan lahan eksisting yang terbatas. Alternatif lain yang memungkinkan adalah bekerjasama dengan desa sekitar pasar untuk mencari lahan yang bisa digunakan untuk mengelola sampah pasar, hasil pengelolaan sampah juga bisa meningkatkan pendapatan warga sekitar dengan mekanisme tersebut. 
Redesain Pasar Mangiran di Bantul D.I.Yogyakarta yang Mewadahi Kegiatan Ekonomi, Sosial, dan Budaya yang Berkelanjutan

\section{KESIMPULAN}

Redesain Pasar Mangiran merupakan salah satu langkah untuk merevitalisasi Pasar Mangiran menjadi salah satu Pasar Rakyat yang diperhitungkan kedepannya sekaligus semakin memberikan kenyamanan yang optimal bagi pengelola, pedagang, dan pengunjung. Redesain Pasar harus mempertimbangkan aspek lokalitas, social dan budaya agar Pasar Rakyat tidak kehilangan jati dirinya yang bersahaja dan berkelanjutan. Konsep Mixed-Used dipilih untuk menjawab permasalahan keterbatasan lahan dan potensi wisata yang cukup tinggi akibat keberadaan Bandara NYIA, sekaligus sebagai wadah potensi ekonomi masyarakat sekitar.

\section{UCAPAN TERIMA KASIH}

Penulis mengucapkan terima kasih kepada : Tuhan Yang Maha Esa berkat rahmat dan pendampingannya penulis dapat menyelesaikan penulisan jurnal ini, LPPM UAJY atas dukungan material dan substansialnya, Bappeda Bantul dan pengelola Pasar Mangiran atas dukungan data dan perijinannya, dan pihak pihak lain yang tidak bisa kami sebutkan satu persatu yang telah membantu selama proses pengabdian dan penulisan ini.

\section{DAFTAR PUSTAKA}

[1] PerMen Dalam Negeri, "Permendag No. 70 Tahun 2013 Tentang Tentang Pedoman Penataan dan Pembinaan Pasar Tradisional, Pusat Perbelanjaan dan Toko Modern," 2013.

[2] Dinas Perdagangan Kabupaten Bantul, "Profil Pasar Rakyat di Kabupaten Bantul," Yogyakarta, 2019.

[3] PerDa DIY, "Peraturan Daerah Istimewa Yogyakarta Nomor 1 Tahun 2017 Tentang Arsitektur Bangunan Berciri Khas Daerah Istimewa Yogyakarta,” 2017.

[4] Dinas Perdagangan Kabupaten Bantul, "Data Hari Pasaran Pasar di Kabupaten Bantul," 2021.

[5] Badan Standardisasi Nasional, "Peraturan Kepala Badan Standardisasi Nasional Nomor 7 Tahun 2015,” 2015.

[6] T. Y. I. A. Muthmainnatul Lathifah, "Perancangan Kembali Pasar Tradisional
Mangiran Di Kecamatan Srandakan Bantul Penekanan Pada Konsep Desain Arsitektur Hijau," Jurnal Arsitektur PENDAPA, vol. 1, 2018, doi:

https://doi.org/10.37631/pendapa.v1i2.112.

[7] PerDa Bantul, "Peraturan Daerah Kabupaten Bantul Nomor 05 Tahun 2011 Tentang Bangunan Gedung,” 2011.

[8] Dinas Pertanahan dan Tata Ruang, "Peta RDTR Kawasan Pedesaan Kabupaten Bantul," 2021.

[9] Webgis Kabupaten Bantul, "Informasi Sempadan Bangunan terhadap Jalan Kabupaten Bantul,” 2011.

[10] Nurul Azizah Rasyid, "Redesain Pasar Larangan Kabupaten Sidoarjo dengan Pendekatan Arsitektur Hijau," Surabaya, 2018.

\section{PENULIS}

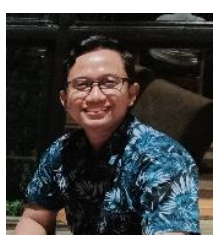

Nicolaus Nino Ardhiansyah, ST.,M.Sc, Departemen Arsitektur, Fakultas Teknik, Universitas Atma Jaya Yogyakarta.

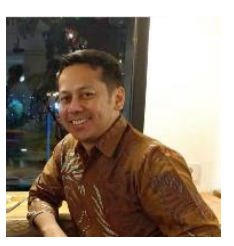

Dr. Rony Gunawan Sunaryo, S.T., M.T., Departemen Arsitektur, Fakultas Teknik, Universitas Atma Jaya Yogyakarta.

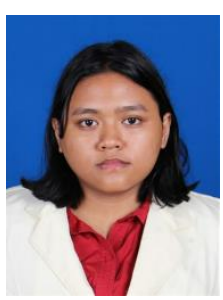

Elisabeth Kirana, Departemen Arsitektur, Fakultas Teknik, Universitas Atma Jaya Yogyakarta. 